Aus dem Landkrankenhaus in Fulda. (Direktor: Dr. Gunkel.)

\title{
Gehäuftes Auftreten von Neuritiden im Bereich der
} oberen Extremität.

Von Dr. Erich Ballmann, Abteilungsarzt der Inneren Abteilung.

Im allgemeinen sind die Neuritiden im Bereich der oberen Extremität ein recht selten beobachtetes Krankheitsbild. In den letżen Wochen ist mir jedoch eine ziemlich starke Häufung dieser Krankheit aufgefallen, und auch Kollegen, die ich darum befragte, teilten mir die gleiche Beobachtung mit.

Bevor ich auf die Beschreibung des Krankheitsbildes und die vermutliche Ursache der merkwürdigen Zunahme seiner Häufigkeit näher eingehe, möchte ich in Folgendem zunächst kurz die Vorgeschichte anführen, wie sie von fast allen Patienten übereinstimmend angegeben wird.

Gewöhnlich kommen die Kranken mit der Angabe, sich seit einiger Zeit nicht melir recht wohl zu fühlen. Sie klagen über eine auffallende Müdigkeit und daneben über e⿳亠̄nen dauernden Schmerz in beiden Armen, in vielen Fällen auch in beiden Schultern, sehr selten jedoch über die gleichen Beschwerden in den Beinen. Von Zeit zu Zeit wird der Schmerz ohne jede deuttich erkennbare äußere Ursache heftiger und wächst oft zu einer solchen Stärke an, daß die Kranken' am liebsten laut aufschreien möchten. Auch nachts treten diese Exazerbationen auf und lassen die Kranken nicht zum Schlafen kommen, sodaß ein. Teil der Patienten durch den dauernden Mangel an Schlaf ziemlich weit herunterkommt. Der Schmerz wird als ziehend, stechend oder bohrend geschildert und hält sich in der Regel an den Verlauf eines Nerven, sodaß die Kranken meist im. stande sind, den Verlauf des erkrankten Nerven anatomisch genau anzugeben. Die grobe Kraft der Arme ist deutlich herabgesetzt, sodaß die Kranken oft außerstande sind, ihre Arme zu den einfachsten Verrichtungen zu gebrauchen. Vor allem das Schreiben fällt ihnen außerordentlich schwer oder ist ganz unmöglich. Frauen klagen gewöhnlich darüber, diß $\beta$ sie sich nicht mehr frisieren können. Alle Kranken klagen außerdem über Parästhesien in den Armen und Händen, vor allem über Gefühl von Pelzigsein. Ein Teil der Kranken ist schon anderweitig längere Zeit wegen Rheumatismus behandelt worden, ohne daß ein Erfolg zu verzeichien gewesen wäre.

Ueber die Ursache ihrer Erkrankung wissen die $\mathrm{Pa}$ tienten keine befriedigende Erklärung abzugeben. Sie sind in der Regel stets gesund gewesen. Intoxikation mit Alkohol, Arsen oder Blei kann in allen meinen Fällen anamnestisch mit Sicherheit aus- 
geschlossen werden. Auch die sonst jetzt stets beschuldigte Grippe 1 fehlt in der Mehrzahl der Fälle, es ist sogar fast die Regel, daß die Kranken angeben, bei keiner der Grippe-Epidemien der letzten Zeit erkrankt gewesen zu sein. Auch Beschäftigungsneuritis läßt sich in allen Fällen ausschließen, und um Ernährungsstörungen, die überhaupt in hiesiger Gegend selten sind, kann es sich ebenfalls nicht handeln.

Nun haben wir in hiesiger Gegend etwa seit Februar dieses Jahres eine nicht geringe Zahl von Enzephalitiden gehabt, meist der lethargischen Form, und es lag nahe, hier an einen Zusammenhang zu denken, zumal ja auch rach typischer Enzephalitis in einem gewissen Prozentsatz der Fälle Polyneuritiden, besonders mit Lähmungserscheinungen, beobachtet werden. Aber auch hier versagt die Anamnese in allen bis auf einen Fall; die Kranken geben mit Bestimmtheit an, niemals irgendwelche schweren Erscheinungen gehabt zu haben, die als Enzephalitis gedeutet werden könnten, sie sind stets dauernd außer Bett gewesen und bis zum Auftreten der Armschmerzen ihrer Beschäftigung nachgegangen. Das klinische Bild aller der hier beobachteten Fälle, auf die ich Raummangels halber nicht" näher eingehen kann, war immer dasselbe.

Es bestanden heftige Schmerzen in den beiden Schultern und Armen, die jede Bewegung unmöglich machten und die Nachtruhe raubten. Von Zeit zu Zeit exazerbierten diese Schmerzen zur Unerträglichkeit. Daneben bestanden Parästhesien. Die Kranken hatten las Gefühl, als ob die Hände mit Pelz ausgekleidet "und als ob die Gelenke angeschwollen seien.

Die Blutuntersuchung ergab immer 7-8000 weiße Blutkörperchen und eine ausgesprochene Lymphozytose (im Mittel 33,5\% Lymphozyten). Die Lymphozytose ist wohl als postinfektiös oder besser als posttoxisch aufzufassen.

Als Therapie hat sich mir am besten die Behandlung mit Diathermie, Vierzellenbädern und vor allem die Injektion von Solarson bewährt. Es tritt bel dieser Behandlung in etwa 4-5 Wochen Heilung vor den Schmerzen ein, doch bleibt eine gewisse Schwäche und Ueberempfindlichkeit meist noch längere Zeit bestehen.

Es wurden hier also in den letzten Monaten in gehäufter Zahl Neuritiden beobachtet, die besonders die obere Extremität befielen und die, soweit sie daraufhin untersucht wurden, e in e Lymphozytose des Blutes aufwiesen. Eine bestimmte Aetiologie konnte nicht mit Sicherheit festgestellt werden, doch spricht das Blutbild dafür, daß es sich um eine Schädigung der. Nerven durch eine $a b-$ gelaufene Infektion handelt. Steph a $\mathrm{n}$ hat, nach einem Referat in Nr.30 der Medizinischen Klinik, bei einem Vortrag im Aerztlichen Verein zu Frankfurt ein Krankheitsbild geschildert, das mit schweren Allgemeinsymptomen einherging ohne wesentlichen Organbefund. Ein Teil der von ihm zitierten Fälle zeigte polyneuritische Symptome. Er führte diese Krankheitsbilder auf überstandene schwere Grippe zurück. Bei allen diesen Fällen fand er nach 5 Minuten langer Stauurg des Armes zahlreiche punktförmige Blutaustritte. Nach einer Aussprache mit Dr. Stephan führt er diese Blutaustritte auf Endothelschädigungen zurück. Er konstatierte gleichzeitig damit ganz charakteristische Veränderungen im Gerinnungssystem des Blutes. Ich habe daraufhin die drei zur Zeit noch in Behandlung stehenden Fälle untersucht und auch bei ihnen ausgedehnte Hautblutungen nach Stauung feststellen können. Gerinnungsversuche konnte ich aus äußeren Gründen noch nicht vornehmen.

$\mathrm{Da}$ in hiesiger Gegend Enzephalitiden beobachtet wurden und die Anañnese eine Falles auf eine ambulant durchgemachte Enzephalitis hinweist, erscheint es nicht ausgeschlossen, daß alle diese Fälle auf einer Schädigung der Nerven durch das Virus der. Enzephalitis beruhen, zumal ja als Folge der Enzephalitis typische Neuritiden wiederholt beobachtet worden sind 